\title{
A descentralização do saber
}

\author{
Cecilia Noriko Ito Saito
}

Martín-Barbero, Jesús

A comunicação na educação.

Trad. por Maria Immacolata Vassalo

de Lopes e Dafne Melo.

São Paulo, Contexto, 155 p., 2014.

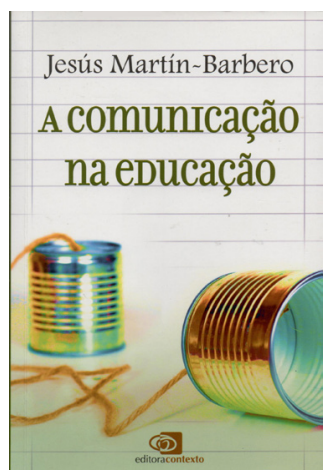

Resumo: Martín-Barbero destaca a transformação da educação na passagem de uma sociedade de sistema educacional para uma sociedade educativa e os deslocamentos das especificidades do lugar do aprendizado, que reconfiguram a hegemonia e a legitimação do saber. Hoje, as redes midiáticas expõem as multiplicidades de canais de circulação e descentralização de saberes num novo ecossistema comunicativo de desafios e interações, o que reforça a importância do espaço comunicacional de compartilhamento dos saberes.

Palavras-chave: comunicação: educação; ecossistema comunicativo.

Abstract: Decentralization of knowledge. - Martin-Barbero highlights the transformation of education in the passage from an educational-system society to a learning society, and the displacements in the specificity of the place of learning, which reconfigure the hegemony and legitimacy of knowledge. Nowadays, media networks expose the multiplicity of circulation channels and the decentralization of knowledge towards a new communicative ecosystem, with challenges and interactions, that reinforce the importance of the communication space of knowledge sharing.

Keywords: communication; education; communicative ecosystem.

Jesús Martín-Barbero é um dos principais pensadores contemporâneos na área da Comunicação. Doutor em Filosofia e em Antropologia e Semiótica, Martín-Barbero foi o fundador do Departamento de Comunicação da Universidad del Valle na Colômbia. 
Espanhol de nascença, reside na Colômbia desde 1963, período em que começou a formação dos seus estudos acadêmicos sobre comunicação, educação e cultura. O desenvolvimento progressivo de suas pesquisas tem destacado sua relevância no cenário internacional e nos estudos latino-americanos do campo comunicacional.

No livro A Educação na Comunicação, o autor discute questões fundamentais que envolvem a Educação, tais como a alfabetização e o papel do livro e da escola, relacionando-as aos temas do universo da comunicação, como aqueles relativos à televisão e às novas tecnologias, estendendo ainda sua reflexão a questões de sociedade. Nesse sentido, debate conceitos variados com autores de outras áreas, a exemplo do educador brasileiro Paulo Freire, e aponta relações entre a comunicação e a educação a partir das transformações que afligem e fundamentam a contemporaneidade.

A interação frequente entre estes dois campos é ressaltada como uma nova forma de aprendizado que exige o fortalecimento de procedimentos escolares ligados às mentalidades, hábitos e ações do presente. Ao citar Fernando Savater e sua ênfase nas transformações que o modelo humanista baseado na leitura de livros vem sofrendo, Martín Barbero endossa a visão de que a verdadeira educação humanista implica no corpo-a-corpo que se estabelece entre a juventude curiosa e os dispositivos que lhe são oferecidos, pois não se aprende por imposição, mas, por contaminação. No seu entender, a escola deixou de ser o lugar de legitimação do saber, pois existe uma multiplicidade de saberes circulando por outros canais, difusos e descentralizados. A contaminação entre educação e comunicação reconfigura o saber enquanto processo comunicativo.

De fato, ao longo das quatro partes em que o livro está estruturado, o autor enfatiza a crescente importância da cultura audiovisual digital para a educação, enfatizando a evolução dos sujeitos quando estimulados a ler e interpretar utilizando as variações impressas, digitais e hipertextuais. O saber se comunica e se descentraliza com o livro transformado em e-book, dando ensejo a um modelo de sobreposição comunicativa integrando os universos digital, audiovisual, videogames, redes sociais, tecnologia móvel e internet. Insinua-se assim a necessidade de transformação da escola de acordo com as mudanças do ecossistema comunicativo contemporâneo. O autor pontua como, reforçando a primazia da escola e de sua ação educativa, todos esses modelos são peças-chave da incessante reorganização dos saberes no século XXI.

A tecnologia e as novas linguagens estão modificando o estatuto dos saberes e apontando para um novo modo de relação do ensino formal com os processos simbólicos. O saber centralizado, controlado pelos dispositivos de poder é agora descentralizado, circulando fora dos livros. A mudança não cancela os livros, mas sim a sua centralidade e linearidade ordenadora. A atenção se volta para a estigmatização que ronda tal mudança no universo escolar, principalmente em relação ao desconhecimento da complexidade social e epistêmica dos dispositivos e processos. O aprendizado escapa das demarcações por idade e por delimitações temporais, reforçando o apagamento das fronteiras 
disciplinares e outras demarcações modernas que datam de mais de dois séculos de linearidade e ordenamento tradicional. Nessa sociedade descentrada e mediada pelo ambiente tecnológico, a proximidade entre a vivência tecnológica e o saber tradicional ampliam as capacidades sociais da comunicação e aumentam as possibilidades transformadoras da educação. O autor procura demonstrar como um trânsito contínuo de mudanças afeta o sistema de aprendizagem. Através de espaços cotidianos, coletivos, individuais e midiáticos, a aquisição de instrução no mundo contemporâneo só poderá acontecer de maneira plena por meio das contribuições dos saberes, num processo educativo em consonância com a comunicação e suas mídias.

Em suma, o livro assinala novos modelos de comunicação e educação que devem interessar quem quer que se dedique a refletir sobre os muitos caminhos do conhecimento. O autor redesenhou, numa cartografia complexa, os mapas das mediações e midiatizações nos diferentes lugares em que a comunicação exerce uma presença decisiva.

Cecilia Noriko Ito Saito é pós-doutora na PUC-SP e na Uniso. É pesquisadora do Centro de Estudos Orientais da PUC-SP.

cnisaito@gmail.com 